\title{
Mapping the emergence of interpersonal values during transgression: Inputs to teaching Filipino psychology and values education
}

\section{Rungduin, Teresita T.}

Research Center for Teacher Quality, Philippine Normal University, Philippines (rungduin.tt@pnu.edu.ph) Rungduin, Darwin C.

Colegio de San Juan de Letran, Philippines (darwinrungduin@yahoo.com)

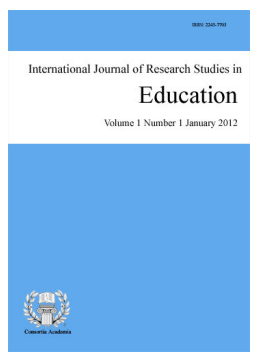

ISSN: 2243-7703 Online ISSN: 2243-7711

OPEN ACCESS

Gravidez, Ivy Rose B.

Philippine Normal University, Philippines (gravidezivyrose@yahoo.com)

Devera, Christopher L.

Colegio de San Juan de Letran, Philippines (christopherdevera@ rocketmail.com)

Ronquillo, Paulene I.

Colegio de San Juan de Letran, Philippines (pauleneronquillo@ rocketmail.com)

\section{Abstract}

This study aimed to identify the interpersonal values that emerge during transgression. Using the Filipino indigenous concept of kapwa (shared identity with others), specifically the ibang-tao/hindi ibang-tao (not one of us/ one of us) dimensions, the respondents were given two vignette stories whose transgressor is characterized in the two dimensions. They were asked to free list the values that they think can be identified in the vignette stories. Using thematic analysis the values were segregated based on ibang-tao (not one of us) and hindi ibang-tao (one of us) types of relationships. Results reveal that more interpersonal values are aroused in the hindi ibang-tao (one of us) type of relationship than the ibang-tao (not one of us) type. Specific interpersonal values were presented and discussed. Relationships formed were deemed important and values related to understanding and forgiving the person became salient. Implications to teaching values education with regard concepts of forgiveness and relationships, and Sikolohiyang Pilipino in relation to indigenizing concepts courses were mapped out.

Keywords: kapwa; transgression; values; ibang-tao/hindi-ibang tao 


\section{Mapping the emergence of interpersonal values during transgression: Inputs to teaching Filipino psychology and values education}

\section{Introduction}

In many circumstances, people are challenged by situations leading to conflict that may result to the emergence of characteristics showing their values. In different interactions that people have with others, facing the conflict and resolving individual differences seem to be a default characteristic in establishing and maintaining relationships. These circumstances may occur in the presence of transgression. Transgression is defined as an act where there is an offense made to a victim or an individual by an offender that yields to negative consequences. In these cases, there is a noted violation of values, or agreement which the victim can identify with (Okimoto \& Wenzel, 2008). In a more parsimonious view, anything that has yielded hurtful feelings in a person's being causing impairment or conflict in the perspective of interpersonal relationships (Boon \& Holmes, 1999) is believed to be a transgression.

In the study of McCullough, Fincham, and Tsang, (2003), using the context of forgiveness, the bearing of transgression differs through which the act is seen, as coming from the offender, and as is directed towards others or a victim. The ability to appreciate effort of a transgressor to seek for forgiveness therefore relies on the ability to see what the person is also going through as may be being punished by the transgression act. Thus, there is significant difference in how one perceives a transgression depending on the varying views from the transgressor himself or herself, the victim and vice-versa (Takaku, 2001; Riek, 2010). As such, how transgression is viewed is dependent on the basis of relationship characteristics (McCullough et al., 2003) or succinctly the degree of relationship one has with the transgressing party.

While it is true that people have the tendency to equally treat people (Daniel, Schiefer, \& Mo, 2010), regard has been given in the manner and how relationships are being characterized. Consequentially, it is inevitable to make biases especially when one is to resolve a substantial decision or matter such as transgression. In the study conducted by Bennett and Sani (2008), support was provided for self-categorization theory that child's formations of the in-group do certainly differ over relative perspectives, both with value to trait- and behavior-based judgments. It is also consistent to the study of Patterson and Bigler (2006) that social categorization produces intergroup biases among children. Findings from the study of Wyer (2010), shows that in-group members are easily persuaded than out-groups. These harmonious results support our notion that social categorization may have implications in the assessment of transgression.

In the process of prosocial behaviors, in general, it appears that empathic reaction is an important springboard. Emphatic reactions found to rely on how much one has evaluated the degree of relationship one has towards the transgressor (Strelan \& Lawani, 2010). Particularly, these studies that have explored the relationship of empathy and group categorization (Cottom, Dazeley, \& Tarrant, 2009; Yabar \& Hess, 2007), have identified that stronger emphatic reaction is found among people who are considered part of the in-group. This reaction may possibly hold true in the context of forgiving others. The intention to forgive a transgressor will actually depend to the degree of relationship that one has with the transgressor. In the Filipino context, the conceptualization of hindi ibang-tao (one of us) and ibang-tao (not one of us), similar to in-group-out-group concept, people may manifest more emphatic reaction towards the transgressor if they have categorized their relationship as hindi ibang-tao (one of us) and consequently lower emphatic reaction with the ibang-tao (not one of us). Enriquez (1994) emphasized that Filipinos value relationships and that it is central to the understanding of the conceptual distinctions between who are considered "outsiders" (ibang tao) and one-of-us (hindi ibang tao). His work on the levels of kapwa (shared identity with others) became a pioneering work in understanding how Filipino values are formed and the way Filipinos see their relationships. 
Values have been part of one's identity since it supports the individual's referential criteria on certain attitudes and behaviours (Sagiv \& Schwartz, 1995). As future teachers, pre-service teachers should create classrooms that support ethical relationships with children (Shaun, 2011). On the other hand, beyond the classroom setting, activities and/or relationships of pre-service teachers should also be taken into considerations when they become professionals. Based on these arguments, the researchers formulated a concept that would trigger the interpersonal values of the pre-service teachers using the Filipino indigenous concept of kapwa (shared identity with others), specifically the ibang-tao/hindi ibang-tao (not one of us/ one of us) dimensions. In many circumstances, values are regarded as a reference point of the person before actually doing things. Likewise, it directs the person's actions and further roots their characters, seeing its worth in the identity of the individual. The values a person posseses is integral to the choices he or she makes in interacting with others and dealing with life's challenges.

Several studies have been conducted to link certain values such as empathy (Konstam, Holmes, \& Levine, 2003), justice (McCullough, Exline, Hill, \& Worthington, 2003), religiosity (Macaskill, 2007), and openness to experience (Kendall, et al. 2004) to forgiveness. All of which are seemingly influential on the forgiveness process. However, there is a dearth in literature concerning the dynamics of transgression and the emerging values that will surface in the onset of transgression exposition in the individual. Since most of the studies (Williamson \& Gonzales, 2007; Konstam et al., 2003; McCullough et al., 2003; Macaskill, 2007; Kendall et al., 2004) about forgiveness constitute findings of values specified in the forgiveness experiences. Studies (Reysen \& Branscombe, 2008; Sagiv \& Schwartz, 1995; McCullough et al., 2003) would affirm that a sense of strong collectivism and individualism among people would determine the extents of forgiveness which are central to the forgiveness process and may affect the probability to forgive a transgressor. As such, the determination of self-oneness to a certain group or entity and even non identification would entail repercussions in the forgiveness of transgressions (Netto \& Mullet, 2004).

The degree of perceived similarity among people and their perspective taking are foundations of relational orientation. This paves the way for closer relationships to occur (Gehlbach, Brinkworth, \& Harris, 2012). Seemingly, a close relationship or a "hindi ibang tao" relationship would likely be a precursor to offend both parties. On the other hand, Zigarovich and Myers, (2011) asserted that a person's intention of adaptively dealing with the situation is in reference with their transgressor's character. Such is seen as a contextual clue that is relatively influential in one's conflict handling strategy. Therefore, in the lens of interpersonal dealings, values are integral to enhancing their relationships.

In the course of understanding relational models are taken into consideration. Mental representations are perceived to be "relational models" stemming from an aggregated emotional relationship between and among people. The everyday relationship may influence a person's need for relatedness (Split, Koomen, \& Thijs, 2011). The degree of relatedness between them predicts the likelihood of perception-transmission among teachers in terms of their engagement, emotions and needs (Klassen, Frenzel, \& Perry, 2012). As need for relatedness is sufficed, it is presumable that "hindi -ibang-tao" (one of us) connotation with others will come to surface. Consequently, the propensity of emphatic reactions will be illustrated. And, as mentioned earlier, the latter becomes a related with other values.

In a similar perspective, strong in-group identification yields heightened regard for those perceived to be involved in their "social circles" (Kinket \& Verkuyten, 1999). This identification would refer to the scope of whether the individual resembles similarity in terms of personality, physical attributes and demographic variables. Given the condition, in-group categorizations of relationships are manifested. Apparently, the notion of social categorization has contributing effects in the observance of bullying among students, group aggression against those they consider to be not one of them, or ostracizing those who do not share common beliefs and ethnicity. Such that, out-group members are susceptible in bullying acts (Huitsing \& Veenstra, 2012). In this case, categorization of relationship becomes a standpoint of transgression acts. 
While different views of the nature of transgression are present, still a gap exists on the knowledge about the values brought about by the act and the consequential effects of categories. Such is prominent in the type of relationship being manifested among individuals. Likewise, the researchers posit that same dynamics of forgiveness in relation to social categorization are likely to be obtained in view of transgressions. Emotional transgression was the focus of the study (i.e, like of agreements, etc.) specifically in relation to paralleled values and dyadic relationships.

\section{Methodology}

\subsection{Research Design}

The study is exploratory in nature since the goal is to make sense of the values perceived by the students that are triggered given the stories about transgressions. Exploratory research was used to define the experiences respondents go through when knowledge about human relationships is analyzed. In the case of this study, the mental listing of values were listed upon reading vignettes concerning forgiving other people who are considered ibang-tao (not one of us) and hindi ibang tao (one of us).

\subsection{Participants}

Sixty two university students, taking psychology from a teacher education institution were recruited to participate in this research study. Their participation was given course credits. Females occupied largely the composition of samples, with a percentage of $79 \%$. Ages range from 16-24 with a mean of 17 years old. While the participants were majoring in psychology, their background in the program is considered limited since they were all in their sophomore year.

\subsection{Instruments: Manipulation and Perceived Values Measure}

Social categorization/kapwa. There are two vignette stories that were developed containing kapwa-related themes. The measure for manipulation identifies whether this characteristic is prominent among the respondents. The kapwa (shared identity with others)-themed stories describe the extent of the relationships manifested in the characters of the story, emphasizing a hindi ibang-tao (one of us) relationship. The perceived values measure is a free listing survey of the perceived values in the vignette stories. The number of responses was dependent on the subjects.

\subsection{Procedures}

The researchers developed vignette stories to simulate conditions that will suffice the understanding of the study's issues. Two vignette stories were constructed. The relationship among the characters was established in particular, the ibang-tao (outgroup), and hindi ibang-tao (ingroup). The language utilized in the stories was Filipino. The length of the story was checked through word counts. Both stories depicted same transgression situation involving one one-of-us/hindi ibang-tao character and the other with not-one-of-us/ibang-tao characters respectively. The stories were given to two groups of students, with each group being exposed to an outgroup vignette and the other group to an ingroup vignette. The students gave their consent to be part of the study and were debriefed after their participation.

\subsection{Data Analysis}

There were two sets of responses generated that were clustered - one from the HIT group and another from the IT group, according to their underlying themes; afterwards the frequencies were counted. Validity of the frequencies were established using Yoshikoder, a cross-platform multilingual content analysis program (yoshikoder.org., 2014), that generates word frequency counts and correspondence between words in a text. The 
accumulated occurrences were ranked. The values obtained were compared in terms of their similarity and differences in the occurrences in relationship characterization, the HIT and IT. Percentage allotment of the values were also counted and presented.

\section{Results and discussions}

The present study claims that empathy is the basic ground of most, if not all, values that are being aroused in any kind of circumstances involving interpersonal relationships. Since the relationship between social categorization and empathy has been strongly established across studies (Tarrant, Dazeley, \& Cottom, 2009; Yabar \& Hess, 2007; Strelan \& Lawani, 2010), there is the assumption about its persistent interconnection with the values that are present in social categories. That is - when a person is considered an in-group member, higher empathic reaction will be developed and therefore, many values would be generated as opposed when the person is perceived as an out-group.

Table 1 presents the established values of hindi ibang-tao (one of us/ingroup) extracted from the vignette stories. Transgressors were present in the vignette stories in order to elicit the values connected with present in the participants. The evident values are concluded to be significant for conflict resolution with a total frequency of 104. There were 32 values hauled out from the responses. Out of those 32 values, the researcher extracted 6 values only due to the grounds of the study. Grounds for the omitted values include a number of the specified values that were chiefly predisposed by the vignette stories. Same values have been identified in the ibang-tao (not one of us/outgroup) with the total frequency of 85 .

\section{Table 1}

Comparison of the Frequencies and Percentages Between Hindi Ibang-tao and Ibang-tao

\begin{tabular}{|c|c|c|c|c|}
\hline \multirow[t]{2}{*}{ Values } & \multicolumn{2}{|c|}{$\begin{array}{l}\text { Hindi-ibang-tao (HIT) } \\
\text { (one-of-us) }\end{array}$} & \multicolumn{2}{|c|}{$\begin{array}{l}\text { Ibang-tao (IT) } \\
\text { (not-one-of-us) }\end{array}$} \\
\hline & $f$ & $\%$ & $f$ & $\%$ \\
\hline Understanding & 33 & 31.73 & 23 & 27.06 \\
\hline Family Relation & 19 & 18.27 & 16 & 18.82 \\
\hline Forgiveness & 20 & 19.23 & 15 & 17.65 \\
\hline Emotional Sensitivity & 12 & 11.54 & 4 & 4.71 \\
\hline Trust & 11 & 10.58 & 15 & 17.65 \\
\hline Concern For Others & 9 & 8.65 & 12 & 14.12 \\
\hline Total f: & 104 & & 85 & 189 \\
\hline
\end{tabular}

As the outcome values for HIT, understanding was ranked first in the identified and radically selected values. Perhaps, the leading notion on this value is that there is a need to empathically understand whatever the present perpetrator did (Exline, Baumeister, Zell, Kraft, \& Witvliet, 2008). Thus, the offenses were seemingly forgivable. In addition, understanding an offender that is a part of the in-group is easier to carry out. In the contrary, understanding value in IT presumes that the tendency to forgive a transgression varies upon how similar the offense committed by the transgressor to the victim's past experiences on committing some wrongdoing. Thus, the offended individual's higher perceived similarity of transgression causes higher tendency to understand and forgive (Exline et al., 2008). Given these, IT is exceptionally blatant that the understanding as a value of HIT is significantly higher than of the IT. Understanding an in-group offender is easier than when understanding an out-group offender.

For the participants' concept of Hindi Ibang-Tao (HIT), emotional sensitivity was salient in their response. This may possibly be due to the intimate interpersonal relationship. Emotional sensitivity is palpably significant for conflict resolution as considered by the participants. With regard to the emotional sensitivity, their concept of Hindi Ibang-Tao (HIT) is extremely evident. Consequently, the choice of emotion to employ may immensely vary on who perpetrated the transgression. The tendency then is to be more emotionally sensitive especially if the offender is a part of the in-group. In contrast, emotional sensitivity appears to be an insignificant value bound 
for an out-group. Hence, if the offender is ibang-tao (IT), as seen in the results, it is obvious that the offended individual is less likely to be emotionally sensitive.

The concept of concern for others in the HIT is given less effort to grant. Since the offender is part of the in-group, there is less demand for consideration because the at hand values is already present. Therefore, this value was not highlighted anymore as compared in the IT which frequency count was quite higher and we assert that this result was affected by the framing of the vignette story.

Filipino's value of family relations (Pe-Pua \& Marcelino, 2000), which we found at large amount of bearing in terms of frequency was presumed to be influential to an individual's perception towards interpersonal relationships that might also be relevant when referring to a transgressor. Stability is indeed needed for upholding of social harmony according to Hughes (1975) as cited by Ahmed, Azar, and Mullet, (2007). Since the family is the smallest unit of the society, thus, harmony should always commence within. Perceivably, the values is innate to a member of the family since it is likely to happen that a family member will consider the stability and harmony of the family and would rather forgive or endure transgression done by the other family member (Fu, Watkins, \& Hui, 2004). In both groups' value of family relations, we assume that an offended individual's discernment towards a transgression was developmentally influenced by the quality of relationship that he has with his family. Perhaps in ibang-tao (IT), the offended individual cannot see the commonality between him and his offender neither the characteristics of the offender to be a friend or a family member. Thus, forgiving is hard to grant. Consequently, the conception of forgiveness as a value under IT provides complexity in granting it particularly in an out-group relationship.

In the study of Hall and Fincham (2006), they suggested that when an infidelity among couples is attributed externally, meaning the infidelity is not sincerely intended or motivated, then forgiveness is more likely to happen. This is also consistent with the study of Fincham, Paleari, and Regalia (2002) wherein they examined forgiveness in marriage, and they found out that attribution processes is directly linked to forgiveness. When the blame is directed to the transgressor, discounting the transgressor's intention, then there would be a difficulty to forgive (Boon \& Sulsky, 1997). Thus, offender-focused attributions (Fincham et al., 2002) or what we may consider as internal attribution directed to the transgressor would lower the chance of forgiving. On the other hand, when the relationship between two individuals is not actually meaningful, then likelihoods of forgiving is negligible (Frommer, 2005). If there is implied hierarchy in perception of relationship which we posit as an indication of inclusion to outgroup member, then it serves as a predictor for outgroup negativity (David, Schiefer, $\&$ Mo, 2010) which might later lead to unforgiveness.

In relation to the present study, these findings support our notion that an in-group member, an intimate partner for instance, would involuntarily arouse values that would find ways to ascribe transgression into something that is much reasonable to upsurge forgiveness, which is one of the major values that we identified. It also follows the fact that the importance of the relationship which later leads to the intention for reconciliation will lead to forgiveness. Unlike when the transgressor is categorized as an out-group member, less specific values are being considered because the relationship seemed to be insignificant, and it would no longer bother the offended individual if he forgives or not. This confirms that when a person possesses the value of being embedded, or the regard for the incorporation of the collective goals rather than individual goals (Daniel, Schiefer, \& Mo, 2010), for example in our case is the goal for maintaining the relationship, and then there is greater probability of forgiveness.

Several studies highlighted empathy as an emotion that can underpin the development of positive attitudes (Gibbons, 2011; Hewstone, Fincham, \& Jaspars, 1981) towards out-groups (Tarrant, Dazely, \& Cottom, 2009). Three of the identified values in our study, specifically understanding, emotional sensitivity and concern for others, were supposed to be extricated from empathy. As emphasis is given on emotional empathy, which refers to emotional responses to another person that either are similar to those the other person is experiencing (parallel empathy) or are reaction to the emotional experiences of other person (reactive empathy) (Stephan \& Finlay, 
1999), it appears that these three values are being inclined by the given definitions.

With regard the values extracted from the out-group (ibang tao) the values also focused on understanding the transgressor while valuing family relationships. Forgiving the transgressor also emerged as a value when acts of injustice (not paying what one is due) are committed. Being emotionally sensitive with the needs of others and expecting others to do so too emerged as an integral value in acts of transgressions while trust that one will be aware of the act of transgression seemed to be a value considered to be important among the respondents. Lastly, the free listing included concerned for others which is a relevant characteristic in relating with the out-group.

In favor of our expected outcome, the result shows that values being exhibited in the context of hindi ibang-tao (ingroup) are in greater number of frequency, 104 as compared with the frequency of ibang-tao (outgroup) which is 85 , and the large discrepancy between these quantities was evidently significant.

The results visibly show the differentiation of specific values in terms of its occurrence which turned to be in greater frequency when referring to hindi ibang-tao. Major values which we identified as understanding, family relation, forgiveness, emotional sensitivity, trust, and concern for others, encompass specific values which weigh dependently on the pre-established social category - forming a strata that provide much emphasis in characterized in-group relationships. Relatively high discrepancies of the frequencies have been obtained between the in-group and out-group, and it suggests that values being stimulated at a higher rate would predict greater level of relationship.

It appeared that forgiveness is also a value to be included. It emerged twenty times in the responses pertaining to HIT. In this case, since a vignette story was presented, forgiveness is possibly the form of dissonance reduction based on the participants' point of view on their concept of Hindi Ibang-Tao (HIT) (Takaku, 2001). Whereas IT which value for forgiveness was relatively lower than HIT justified our belief that out-group member is much difficult to forgive.

Another value that we characterized is trust, which involved a person's willingness to be at risk with the trustee's actions or intentions that is positively expected to happen (Kelley \& Huff, 2003). Inconsistent with our result in which we found out that trusting behavior towards ibang-tao has higher frequency as compared to hindi-ibang-tao, confirms the notion of Kelley and Huff (2003) that collectivist cultures such as Filipino culture (Pe-Pua \& Marcelino, 2000), has stronger in-group bias that inhibit the tendency to trust out-group member or what we call ibang-tao. The result was ironic in a sense, but the explanation to the higher frequency of trust in ibang-tao was due to the framing of the vignette stories that trigger the emphasis of trust when confronted with an out-group member. The first story whose main characters were the mother (transgressor) and the son (offended), provoked trusting behaviors were inherent as accustomed in our culture, consequently trust is less prominent. On the other hand, the second story whose main characters were a new classmate (transgressor) and Mato (offended), accentuated trust because this behavior is not supposed to happen, yet it has been depicted and established in the story. This clarification would now justify the previous contradiction; still there is a scarcity of literatures that would answer why an individual finds difficulty in trusting out-group member (Moy \& $\mathrm{Ng}$, 1996).

Among the values that were manifested as commonalities in relationships, understanding, family relations, forgiveness, trust, emotional sensitivity and concern for others arise and that are of different levels respectively. This also implicates in the intent of restoring the relationships as these values should work centrally in interpersonal relationships to be successfully restored. The results implicates in the process of decision making in the limits of dyadic relationships, in particular with interpersonal relationships. Social categorization as incorporated in social encounters and interactions becomes an important factor of reference in the manifestation of values of an individual. Consequently, transgressions may seem to be not an element of basis, as relational orientation would prevail. Nonetheless, the act of transgression in a sense is secondly being regarded, which should be given with equal or emphasized appraisal to be pondered on. As the likelihood, repetition and severity of any transgression is important to take also into account. 


\subsection{Inputs to Teaching Filipino Psychology and Values Education}

Educational institutions are rich with dyadic interactions and relationships aside from its scholarly nature. Since a large amount of time is being devoted by individuals at the onset of their early age in schools (Malm \& Lofgren, 2006), interactions are crucial in the development of one's socio-emotional development. The teacher in particular holds poignant role that mediates interaction of students with them and with others. As every individual are summed of the values that they learn from different contexts, dyadic exchange of values come to perpetuate in classroom relationships among teachers and students vice versa (Brady, 2011) One of the instances by which these values come to surface is when one characterizes the degree of one's relationship as paralleled with transgressions. The study transpires that while similar values ought to emerge in these two relationships, differentiation lies in its manifestation of the values. That is, values remain the same but actions differ in response to examining whether the person is ibang tao (not-one of us) or hindi-ibang-tao (one-of-us).

Taking into consideration that agreeableness of pre-service teachers is an indicator of being forgiving (Costa $\&$ McCrae, 1992) and forgiving among the students is identified as one effective character of a teacher (Walker, 2008); the researchers looked into the variations of kapwa when they forgive. Teachers in training must function as role models of fair knowledge assessment and as mediators in different conflict situations (Gradišek, 2012). Further, students had plenty of memories of teachers who were not too forgiving of their classmates or themselves, but their accounts of favorite teachers reflected a willingness to forgive students for misbehavior (Thompson, Greer, \& Greer, 2004). People who are drawn to teaching professions could share some specific personality traits, values, and virtue (Gradišek, 2012).

Cognizant of the results brought by relational categorization of ibang tao (one of us) and hindi ibang tao (not one of us) concepts, forgiveness is seen to be an underlying factor between the two levels of kapwa (shared identity with others). Subsequently, this underlines forgiveness as one of the values present among interpersonal relationships. Egan and Todorov (2009), proposes forgiveness as having mechanistic function in coping of the students offended with transgression. The school climate requires an emergence of values like forgiveness in dealing with negative emotional outcomes of hurtful actions. As an example, the deleterious effects of bullying in terms of health and psychological wellness of a student can be deterred by facilitating forgiveness. Bullying works on two faces of relationships as any transgression will also be and leaves no exception. Therefore, the difference will work on the range of how these values will be highlighted.

In teaching Values Education, reconciliation and forgiveness should be highlighted. Since forgiveness is triggered by values pertaining to understanding the transgressor and giving importance to familial relationships, discussions on what is forgivable and unforgivable as well as the processes one goes through in forgiving are suggested to be highlighted. More importantly, being forgiving was also seen as a value that should be encouraged especially in improving relationships between family members and the people that the students consider "one-of-us."

When it comes to teaching Filipino Psychology, it is imperative to highlight the role of kapwa in responding to transgressions. The study emphasized that the people we forgive the most are people we consider hindi ibang tao, which may implicate that once a relationship reached a level where the other is considered a "one-of-us," the degree to which the person will be understood for his or her mistakes will increase. The dynamics of interpersonal forgiveness may further be evaluated and discussed with reference to the values Filipinos have.

The challenge of transgression's nature and extent perceivably impede forgiveness or relational restoration. In keeping pace with these possibilities, it implicates that pre-service and in service teacher should learn managing the magnitude of categorization. In making this happen, empathy incessantly requires its significance. As most researches would affirm that empathy works as a threshold for positive values (Gibbons, 2011; Hewstone, Fincham, \& Jaspars, 1981); (Egan \& Todorov, 2009). This may appear to be valuable to student-to-student relationships and to educators themselves likewise. It is noteworthy, that with diffused 
categorization, they can exhibit equal and unconditional positive regard with their students.

\section{Conclusions and recommendations}

One objective of this study was to examine the surfacing values that can be found when there is transgression, and how it differs in terms of its manifestations towards social categories, particularly hindiibang-tao (in-group) and ibang-tao (out-group). The present study hypothesized: first, values per se that are aroused are partially distinctive towards hindi ibang-tao (in-group) and ibang-tao (out-group); second, transgression done by hindi ibang-tao is much more susceptible in considering values compared with ibang-tao; lastly, these values are constant in both social categories, but it varies on how it is being exhibited. The hypotheses were confirmed.

Result shows that there are certain values that are present in hindi ibang-tao which are not present in ibang-tao and vice-versa, but majority of the values cited are common by the two groups. It is also evident that values are somewhat being modified when there is social category to consider. These values fluctuate depending on the person who transgressed. General values, for example, empathy, comprise specific values which we found at greater number when pertaining to hindi-ibang-tao. Meaning, a transgressor who is considered to be hindi ibang-tao is being judged in broader aspects, wherein the offended individual looks at different sides of the transgression that took place. Unlike the certain values being observed when the person is ibang-tao, which is found to be slightly minimal. This indicates that regardless of the external and internal factors (i.e intention, peer pressure) that might be the reason why the person transgressed, the degree of relationship between a transgressor and the offended individual would still predict the values that would come out.

With these in mind, importance should be given in discussing kapwa and its central concepts of hindi ibang tao and ibang tao in topics on interpersonal relationships in Values Education. If we are advocating that pre-service teachers should be sensitive to the needs of their students then understanding transgressions and how values are important in forgiving a transgressor should have an integral place in the discussion of what it means to relate with others. In addition, topics in Filipino psychology courses should be grounded on indigenizing constructs concerning whom to forgive and why. Lastly, when it comes to discussions under the psychology major course, Sikolohiyang Pilipino, it is imperative to point out and immerse students with the theory of kapwa and how integral it is in understanding and deciphering the Filipino core values.

The values that were triggered in this study would most probably predict the possible values or associated responses that will manifest when some of pre-service students or colleagues (who might be considered Ibang-tao or Hindi-ibang-tao) transgressed them when they become professional teachers. Through these, future researchers could create an intervention programs that may strengthen the positive values of the pre-service teachers. Research shows that teachers who make domain-inappropriate responses to student transgression undermine their credibility as socialization agents (Killen, Breton, Ferguson, \& Handler, 1994). Confronting problems directly or educating a transgressor is more appealing than public humiliation. The study focused on using vignette stories to prompt values responses related to transgression and forgiveness. The identification of these values could be further analyzed using actual recall of personal experiences of transgression and forgiveness which may provide a more in-depth and varied context of the values observed in this study.

NOTE: The study is a collaboration between the two assistant professors (Rungduin and Rungduin) from the two identified institutions and their students (Gravidez, Devera, and Ronquillo). This research is a product of the Research Camp, a Department of Behavioral Sciences initiative under the Philippine Normal University. 


\section{References}

Ahmed, R. A., Azar, F., \& Mullet, E. (2007). Interpersonal forgiveness among Kuwaiti adolescents and adults. Conflict Management and Peace Science, 24(3), 159-170. http://dx.doi.org/10.1080/07388940701468385

Bennett, M., \& Sani, F. (2008). The effect of comparative context upon stereotype content: Children's judgments of ingroup behavior. Scandinavian Journal of Psychology, 49(2), 141-146. http://dx.doi.org/10.1111/j.1467-9450.2008.00628.x

Brady, L. (2011). Teacher values and relationship: Factors in values education. Australian Journal of Teacher Education, 36(2), 56-66. http://dx.doi.org/10.14221/ajte.2011v36n2.5

Boon, S. D., \& Holmes, J. G. (1999). Interpersonal risk and the evaluation of transgressions in close relationships. Personal Relationships, 6, 151-168. http://dx.doi.org/10.1111/j.1475-6811.1999.tb00184.x

Boon, S. D., \& Sulsky, L. M. (1997). Attributions of blame and forgiveness in romantic relationships : A policy-capturing study. Journal of Social Behavior and Personality, 12(1), 19-44.

Costa, P. T., \& McCrae, R. R. (1992). Revised NEO personality inventory (NEO-PI-R) and NEO five-factor inventory (NEO-FFI) professional manual. Odessa, FL: Psychological Assessment Resources.

Daniel, E., Schiefer, D., \& Mo, A. (2010). Special issue article cultural values and outgroup negativity : A cross-cultural analysis of early and late adolescents. European Journal of Social Psychology, 40, 635-651. http://dx.doi.org/10.1002/ejsp.745

Egan, L. A., \& Todorov, N. (2009). Forgiveness as a coping strategy to allow school students to deal with the effects of being bullied: Theoretical and empirical discussion. Journal Social and Clinical Psychology, 28, 198-222. http://dx.doi.org/10.1521/jscp.2009.28.2.198

Exline, J. J., Baumeister, R. F., Zell, A. L., Kraft, A. J. \& Witvliet, C. V. (2008). Not so innocent: Does seeing one's own capacity for wrongdoing predict forgiveness? Journal of Personality and Social Psychology, 94(3), 495-515. http://dx.doi.org/10.1037/0022-3514.94.3.495

Exline, J. J., Worthington, E. L., Hill, P., \& Mccullough, M. E. (2003). Forgiveness and justice: A research agenda. Personality and Social Psychology Review, 7(4), 337-348. http://dx.doi.org/10.1207/S15327957PSPR0704_06

Gehlbach, H., Brinkworth, M. E., \& Harris, A. D. (2012). Changes in teacher - student relationships. British Journal of educational Psychology, 82(4), 690-704. http://dx.doi.org/10.1111/j.2044-8279.2011.02058.x

Fincham, F. D., Paleari, F. G., \& Regalia, C. (2002). Forgiveness in marriage: The role of relationship quality, attributions, and empathy. Personal Relationships, 9(1), 27-37. http://dx.doi.org/10.1111/1475-6811.00002

Frommer, M. S. (2005). Thinking relationally about forgiveness. Psychoanalytic Dialogues, 15(1), 33-45. http://dx.doi.org/10.1080/10481881509348813

Fu, H., Watkins, D., \& Hui, E. K. (2004). Personality correlates of the disposition towards interpersonal forgiveness: A Chinese perspective. International Journal of Psychology, 39(4), 305-316. http://dx.doi.org/10.1080/00207590344000402

Gibbons, S. B. (2011). Understanding empathy as a complex construct: A review of the literature. Clinical Social Work Journal, 39, 243-252. http://dx.doi.org/10.1007/s10615-010-0305-2

Gradišek, P. (2012). Character strengths and life satisfaction of Slovenian in-service and pre-service teachers. CEPS Journal, 2(3), 167-180.

Hall, J. H., \& Fincham, F. D. (2006). Relationship dissolution following infidelity: The roles of attributions and forgiveness. Journal of Social and Clinical Psychology, 25(5), 508-522. http://dx.doi.org/10.1521/jscp.2006.25.5.508

Hewstone, M. F. (1981). Social Categoriozation and similarity in intergroup behaviors: A replication with penalties. European Journal of Social Psychology, 11, 101-107. http://dx.doi.org/10.1002/ejsp.2420110107

Huff, L., \& Kelley, L. (2003). Levels of organizational trust in individualist vs. collectivist societies: A seven 
Mapping the emergence of interpersonal values during transgression

nation study. Organization Science, 7(4), 81-90. http://dx.doi.org/10.1287/orsc.14.1.81.12807

Huitsing, G., \& Veenstra, R. (2012). Bullying in classrooms: Participant roles from a social network perspective. Aggressive Behavior, 38, 494-509. http://dx.doi.org/10.1002/ab.21438

Killen, M., Breton, S., Ferguson, H., \& Handler, K. (1994). Preschoolers' evaluations of teacher methods of intervention in social transgressions. Merrill-Palmer Quarterly, 40, 399-415.

Kinket, B., \& Verkuyten, M. (1999). Intergroup evaluations and social context: A multilevel approach. European Journal of Social Psychology, 29, 219-237.

http://dx.doi.org/10.1002/(SICI)1099-0992(199903/05)29:2/3<219::AID-EJSP925>3.0.CO;2-X

Konstam, H., Holmes, W., \& Levine, B. (2003). Empathy, selfism, and coping as elements of psychology of forgiveness: A preliminary study. Counseling and Values, 47(3), 172 - 183. http://dx.doi.org/10.1002/j.2161-007X.2003.tb00264.X

Macaskill, A. (2007). Exploring religious involvement, forgiveness, trust, and cynicism. Mental Health, Religion \& Culture, 10(3), 203-218. http://dx.doi.org/10.1080/13694670600616092

Malm, B., \& Lofgren, H. (2006). Teacher competence and students' conflict handling strategies. Research in Education, 76, 62-73. http://dx.doi.org/10.7227/RIE.76.6

McCullough, M. E., Fincham, F. D., \& Tsang, J.-A. (2003). Forgiveness, forbearance, and time: The temporal unfolding of transgression-related interpersonal motivations. Journal of Personality and Social Psychology, 84(3), 540-557. http://dx.doi.org/10.1037/0022-3514.84.3.540

Morgan, T. D. (2011). "Everything changed": Relational turning point events in college teacher student relationships from teachers' perspectives. Communication Education, 60(1), 20-50. http://dx.doi.org/10.1080/03634523.2010.497223

Moy, J., \& Ng, S.H. (1996). Short Note Expectation of outgroup behaviour: Can you trust the outgroup?. European Journal of Social Psychology, 26, 333-341. http://dx.doi.org/10.1002/(SICI)1099-0992(199603)26:2<333::AID-EJSP747>3.0.CO;2-1

Neto, F., \& Mullet, E. (2004). Personality, self-esteem, and self-construal as correlates of forgivingness. European Journal of Personality, 18(1), 15-30. http://dx.doi.org/10.1002/per.500

Okimoto, T. G., \& Wenzel, M. (2008). The symbolic meaning of transgressions: Towards a unifying framework of justice restoration. In K. A. Hegtvedt \& J. Clay-Warner (Eds.), Advances in Group Processes: Justice (vol. 25, pp. 291-326). Emerald Group Publishing.

Patterson, M. M., \& Bigler, R. S. (2006). Preschool children's attention to environmental messages about groups: social categorization and the origins of intergroup bias. Child development, 77(4), 847-60.

Pe-Pua, R., \& Protacio-Marcelino, E. A. (2000). Sikolohiyang Pilipino (Filipino psychology): A legacy of Virgilio G. Enriquez. Asian Journal of Social Psychology, 3(1), 49-71. http://dx.doi.org/10.1111/1467-839X.00054

Reysen, S., \& Branscombe, N. R. (2008). Belief in collective emotions as conforming to the group. Social Influence, 3(3), 171-188. http://dx.doi.org/10.1080/15534510802247438

Riek, B. M. (2010). Transgressions, guilt, and forgiveness: A model of seeking. Journal of Psychology \& Theology, 38(4), 246-254.

Sagiv, L., \& Schwartz, S. H. (1995). Interpersonal relations and group value priorities and readiness for out-group social contact. Journal of Personality, 69(3), 437-448. http://dx.doi.org/10.1037/0022-3514.69.3.437

Shaun, M., Pinnegar, E., \& Pinnegar, S. (2011). Exploring ethical tensions on the path to becoming a teacher. Teacher Education Quarterly, 38(4), 97-113.

Split, J. I., Koomen, H. M., \& Thijs, J. T. (2011). Teacher wellbeing: The importance of teacher-student relationships. Educational Psychology Review, 23, 457-477. http://dx.doi.org/10.1007/s10648-011-9170-y

Stephan, W., \& Finlay, K. (1999). The role of empathy in improving intergroup relations. Journal of Social Issues, 55(4), 729-743. http://dx.doi.org/10.1111/0022-4537.00144

Strelan, P., \& Lawani, A. (2012). Muslim and Westerner responses to terrorism: The influence of group identity on attitudes toward forgiveness and reconciliation. Peace and Conflict: Journal of Peace Psychology, 
Rungduin, T. T., Rungduin, D. C., Gravidez, I. R. B., Devera, C. L., \& Ronquillo, P. I.

16(1), 59-79. http://dx.doi.org/10.1080/10781910903485294

Takaku, S. (2001). The effects of apology and perspective taking on interpersonal forgiveness: A dissonance-attribution model of interpersonal forgiveness. The Journal of Social Psychology, 141(4), 494-508. http://dx.doi.org/10.1080/00224540109600567

Tarrant, M., Dazeley, S., \& Cottom, T. (2009). Social categorization and empathy for outgroup members. British Journal of Social Psychology, 48, 427-446. http://dx.doi.org/10.1348/014466608X373589

Thompson, S., Greer, J. G., \& Greer, B. B. (2004). Highly qualified for successful teaching: Characteristics every teacher should possess. Essays in Education, 10. Retrieved from http://www.usca.edu/essays/vol102004/thompson.pdf

Walker, R. J. (2008). Twelve characteristics of an effective teacher: A longitudinal, qualitative, quasi-research study of in-service and pre-service teachers' opinions. Educational Horizons, 87(1), 61-68.

Williamson, I., \& Gonzales, M. H. (2007). The subjective experiences of forgiveness: Positive construals of the forgiveness experience. Journal of Social and Clinical Psychology, 26(4), 407-446. http://dx.doi.org/10.1521/jscp.2007.26.4.407

Wyer, N. A. (2010). Selective self-categorization: Meaningful categorization and the in-group persuasion effect. The Journal of Social Psychology, 150(5), 452-70. http://dx.doi.org/10.1080/00224540903365521

Yabar, Y., \& Hess, U. (2007). Display of empathy and perception of out-group members. New Zealand Journal of Psychology, 36(1), 42-49.

Yoshikoder.org. (2014). What is yoshikoder. Retrieved from http://www.yoshikoder.org

Zigarovich, K. L., \& Myers, S. A. (2011). The relationship between perceived instructor communicative characteristics and college conflict handling styles. Journal of Instructional Psychology, 38(1), 11-17. 